\title{
Diuretic activities of hydro-alcoholic extract and solvent fractions of the roots of Withania somnifera L. (Solanacaea) in rats
}

\begin{abstract}
Background: Withania somnifera (Local name 'Gsawa') is used in folkloric medicine for the management of hypertension in different parts of the world including Ethiopia. This may be due to its diuretic activity. However, it has not been yet scientifically validated for its efficacy and safety.

Objective: The aim of this study was to investigate the diuretic potential of both hydroalcoholic ( $80 \%$ methanol) extract and solvent fractions of the hydro-alcoholic root extract of $W$. somnifera in rats.

Results: The hydro-alcoholic extract increased diuresis significantly at the doses of 400 and $600 \mathrm{mg} / \mathrm{kg}(\mathrm{p}<0.05)$. Similarly, the solvent fractions of the hydro-alcoholic extract -the aqueous and n-butanol fractions- significantly increased urine volume at $400 \mathrm{mg} / \mathrm{kg}$ $(\mathrm{p}<0.05)$. Regarding electrolyte excretion, the larger doses of both hydro-alcoholic extract and aqueous fraction increased natriuresis $(\mathrm{p}<0.05)$. Phytochemical analysis revealed the presence of secondary metabolites including tannins, terpenoids, flavonoids and saponins, which could be the responsible component (s) for the diuretic activity.

Conclusion: The results of the present study indicated that the $W$. somnifera extract is endowed with significant diuretic activity providing evidence for its traditional claim. The increased diuresis effects of the crude extracts and fractions may be attributable for presence of polar phytoconstitutents.
\end{abstract}

Keywords: withania somnifera, hydrochlorothiazide, diuresis, natriuresis and kaliuresis
Volume I4 Issue 3 - 202I

\author{
Khaalid Dayib,' Asfaw Debella, ${ }^{2}$ Solomon M \\ Abay' \\ 'Department of Pharmacology, Addis Ababa University, Ethiopia \\ ${ }^{2}$ Traditional and Modern Medicine Research Directorate, \\ Ethiopian Public Health Institute, Ethiopia
}

\begin{abstract}
Correspondence: Asfaw Debella, Traditional and Modern Medicine Research Directorate, Ethiopian Public Health Institute, P. O. Box 1242; Addis Ababa, Ethiopia,
\end{abstract} Tel+251913544162, Email asfawdebella@gmail.com

Received: January 17, 2021 | Published: May 27, 2021

\section{Background}

Extracellular volume is altered due to clinical conditions such as heart failure, renal failure, hypertension, syndrome of inappropriate anti-diuretic hormone and hypervolemichyponatremia. ${ }^{1}$ The commonly used diuretics as intervention- thiazides and furosemideare associated with many side effects, like disturbances of electrolytes, acid-base and water balance, changes in uric-acid, carbohydrate and lipid metabolism and drug interactions. ${ }^{2}$ Medicinal plants, as used to be good sources of several therapeutic agents, needs to be explored to look for effective and safe diuretics.

Withania somnifera (Solanaceae) is an evergreen, erect, branching, shrub, $30-150 \mathrm{~cm}$ in height. The leaves are simple opposite, alternate and the tip of the leaf is acute, and glabrous up to 8 to $12 \mathrm{~cm}$ in length. Flowers are greenish of lurid yellow with diameter of 4-6mm and 1 $\mathrm{cm}$ long. Roots are cylindrical, straight and unbranched with $1-2 \mathrm{~cm}$ thick. $^{3}$

Asres and colleagues ${ }^{4}$ reviewed that $W$. somnifera is traditionally used for the treatment of headache, malaria and stomachache. People also know that $W$. somnifera has diuretic application. ${ }^{4}$ In the traditional systems of medicine [Unani medicine and Ayurveda], W. somnifera is mentioned as one of the most potent aphrodisiacs. ${ }^{5}$ Experimentally, $W$. somnifera is found to have anti-fertility properties and antiimplantation activity of $W$. somnifera extract. ${ }^{6}$ The root contains several alkaloids including withanine, withananine, withananinine, pseudowithanine, somnine, somniferine, somniferinine. ${ }^{5}$

Leaves are reported to contain withanone, somnitol and several chlorinated withanolides. ${ }^{7}$ The use of $W$. somnifera as health food and herbal tonic alone or in polyherbal or herbomineral formulations is a common practice and there is evidence on its antihypertensive activity in experimental models. However, there is no body of evidence on its diuretic activity. ${ }^{8}$ Taking into consideration of this knowledge gap, this study is intended to evaluate the diuretic activity of $80 \%$ methanol extract and solvent fractions of roots of $W$. somnifera in rats.

\section{Materials and methods}

\section{Experimental animals}

Wistar albino rats of either sex, weighing 180-250g were used for the experiment. The animals were kept in plastic cages at room temperature and on a $12 \mathrm{~h}$ light-dark cycle with free access to pellet food and water at the animal house of Pharmacology Department, School of Medicine, Addis Ababa University. The care and handling of animals were in accordance with internationally accepted OECD420 (2008) guidelines for use of animals.

\section{Plant material collection}

The roots of $W$. somnifera were collected from the outskirt of Addis Ababa, Ethiopia in July 2019. The plant was authenticated by a taxonomist at the National Herbarium, College of Natural and Computational Sciences, Addis Ababa University and a specimen with voucher number KD001was deposited for future reference.

\section{Extraction of the plant material}

The roots of $W$. somnifera were thoroughly washed and sliced to smaller pieces and dried at room temperature in the shade. The dried and crushed roots were then powdered finely and subjected to 
extraction. The extraction was carried out by maceration technique using $80 \%$ methanol. Briefly, the dried powder $(600 \mathrm{mg})$ was soaked in Erlenmeyer flask containing $600 \mathrm{ml}$ of the $80 \%$ methanol solvent for 3days with occasional agitation using shaker (Bibby Scientific Ltd, UK). The mixture was filtered through double layered muslin cloth followed by Whatman (No.1) filter paper. The residue was remacerated for the second and third times with fresh solvent for a total of 6days. The extract was then concentrated using a rotary evaporator (BÜCHI Rota-vapor R-200, Switzerland) under reduced pressure at $40^{\circ} \mathrm{C}$. The concentrated filtrate was frozen in a refrigerator overnight and then freeze dried in the lyophilizer (Operon Co., Ltd, Korea) to obtain freeze dried crude extract. The percentage yield of crude extract was $13.65 \%(\mathrm{w} / \mathrm{w})$, and the dried extract was used for further fractionation.

\section{Solvent fractionation}

The $80 \%$ methanol extract of $W$. somnifera was subjected further fractionation using chloroform, butanol and aqueous solvent based on their relative solubility. Accordingly, a total of $60 \mathrm{~g}$ of the extract was partitioned first between $250 \mathrm{ml}$ of distilled water and $250 \mathrm{ml}$ chloroform using separatory funnel then between $250 \mathrm{ml}$ of distilled water and $250 \mathrm{ml}$ butanol. The organic solvent (chloroform and butanol) filtrate were concentrated to get chloroform phase, butanol phase, and water phase. All fractions were kept in tightly closed containers in refrigerator at $-200 \mathrm{C}$ until used for the experiment.

\section{Acute toxicity test}

Acute toxicity test was performed according to the Organization for Economic Cooperation and Development (OECD) 425 (2008) guideline. Briefly, a single female rat was fasted food but not water for overnight and was loaded with single dose $2000 \mathrm{mg} / \mathrm{kg}$ of the $80 \%$ methanol extract and fractions by oral gavage. It was then observed for any signs of toxicity with in the first $24 \mathrm{~h}$. Based on the results of the single rat, another 4 female rats, fasted overnight, were given the same dose and observed for any sign of toxicity or death for two weeks. The acute toxicity test evaluations were used to generate three dose levels to evaluate diuretic efficacy of the extract: middle dose, which is onetenth of the dose utilized during acute toxicity study. A low and high dose were half and twice of the middle dose, respectively.

\section{Grouping and dosing the experimental animals}

The rats were randomly assigned into five groups of each with six animals to assess diuretic activities of both $80 \%$ methanol extract and solvent fractions. The first group was assigned as negative control and received the vehicle used for reconstitution of extract $(10 \mathrm{ml} / \mathrm{kg}$ of body weight). Positive controls were treated with standard drug, hydrochlorothiazide $10 \mathrm{mg} / \mathrm{kg}$ (HCT-10). The test groups were given three different doses of extract or fractions at doses of $200 \mathrm{mg} / \mathrm{kg}$ (ME200), 400mg/kg (ME400), 600mg/kg (ME600).

\section{Evaluation of diuretic activity}

The method of Lahlou et al. (2007) was employed to assess the diuretic activity. The rats were fasted for $18 \mathrm{~h}$ with free access to water. Before treatment, all animals received normal saline at an oral dose of $15 \mathrm{~mL} / \mathrm{kg}$ body weight, to impose a uniform water and salt load. ${ }^{9}$ Each group was then administered the extract and vehicle by oral gavage. Immediately after administration, the rats were individually placed in a metabolic cage. During this period no food was made available to the animals. The urine was collected and measured at 1, 2, 3, 4, 5 and $24 \mathrm{~h}$ after dosing and stored at $-20^{\circ} \mathrm{C}$ for electrolyte analysis.

The following parameters were determined in order to compare the diuretic effects of the extracts with vehicle. The urinary excretion independent of the animal weight was calculated as total urinary output divided by total liquid administered (Formula 1). The ratio of urinary excretion in test group to urinary excretion in the control group was used as a measure of diuretic action of a given dose of an agent (Formula 2). To obtain diuretic activity, the diuretic action of the extract was compared to that of the standard drug in the test group (Formula 3). ${ }^{10}$

Urinary Excretion $=($ Total urinary output $) /($ Total liquid administered) $\times 100 \%(1)$

Diuretic Action $=($ Urinary excretion of treatment groups $) /($ Urinary excretion of control group) (2)

Diuretic Activity $=($ Diuretic action of test group $) /($ Diuretic action of standard group) (3)

\section{Evaluation of electrolytes}

Sodium, potassium and chloride levels of urine samples were analyzed. The electrolyte concentrations were determined using Ion Selective Electrode (ISE) analyzer (Roche, Germany). A calibration was performed automatically prior to analysis with different levels of standards. Ratios of electrolytes, $\mathrm{Na}+/ \mathrm{K}+$ and $\mathrm{Cl}-/[\mathrm{K}++\mathrm{Na}+]$ were calculated to evaluate the saluretic activity of the different extracts. In addition, $\mathrm{pH}$ was directly determined on fresh urine samples using a $\mathrm{pH}$ meter. Furthermore, the salt content of the extract was determined to rule out its contribution on urinary electrolyte concentration.

\section{Preliminary phytochemical screening}

The qualitative phytochemical investigations of the crude extract, and chloroform, butanol and aqueous fractions of the roots of $W$. somnifera were carried out using standard testsforterpenoids, saponins, tannins, flavonoids, cardiac glycosides, alkaloids, anthraquinones and steroids. ${ }^{11,12}$

\section{Statistical analysis}

Data, expressed as mean \pm standard error of mean (SEM), were analyzed using the Software Statistical Package for Social Sciences, version 20. Comparison of urine volume, electrolyte concentration and statistical significance was determined by one way ANOVA followed by Turkey's Post Hoc multiple comparison test. Linear regression analysis was done for dose dependence test. Significant differences was set at $\mathrm{p}$ values less than 0.05 .

\section{Results}

\section{Acute toxicity test}

The $80 \%$ methanol extract as well as solvent fractions of the hydro-alcoholic root extract of $W$. somnifera produced neither overt toxicity nor death during the 14days observation period following oral administration of a single dose of $2000 \mathrm{mg} / \mathrm{kg}$. This also confirmed that LD50values for the extract and fractions were greater than $2000 \mathrm{mg} /$ $\mathrm{kg}$ in rats.

\section{Effect of $\mathbf{8 0 \%}$ methanol extract on urine volume: diuretic activity}

Eighty percent of methanol extract of the roots of $W$. somnifera produced diuresis (Table 1) which appeared to be dose-dependent $(\mathrm{r} 2=0.950 ; \mathrm{p}<0.05)$. ME200 did not produce a statistically significant diuresis compared to control animals throughout the $24 \mathrm{~h}$ period. Rats treated with ME400 increased diuresis starting from the 1st $\mathrm{h}$ of urine collection $(62 \%, \mathrm{p}<0.05)$ when compared to the control. The ME600 produced diuresis which was significant starting from the $1 \mathrm{st} \mathrm{h}(110 \%$, $\mathrm{p}<0.05$ ) compared with the control. 
Table I Effect of $80 \%$ methanol extracts of W. somnifera roots on $24 \mathrm{~h}$ urine volume in rats

\begin{tabular}{|c|c|c|c|c|c|c|c|c|}
\hline \multirow{2}{*}{ Group } & \multicolumn{6}{|c|}{ Volume of urine $(\mathrm{mL})$} & \multirow{2}{*}{$\begin{array}{l}\text { Diuretic } \\
\text { action }\end{array}$} & \multirow{2}{*}{$\begin{array}{l}\text { Diuretic } \\
\text { activity }\end{array}$} \\
\hline & Ih & $2 \mathrm{~h}$ & $3 h$ & $4 h$ & $5 \mathrm{~h}$ & $24 h$ & & \\
\hline Control & $1.00 \pm 0.07$ & $1.33 \pm 0.06$ & $1.56 \pm 0.05$ & $2.03 \pm 0.04$ & $2.48 \pm 0.03$ & $5.13 \pm 0.04$ & 1.00 & \\
\hline HCTIO & $2.03 \pm 0.04^{\mathrm{a}}$ & $2.55 \pm 0.04^{\mathrm{a}}$ & $2.93 \pm 0.03^{a}$ & $3.39 \pm 0.06^{\mathrm{a}}$ & $4.76 \pm 0.12^{\mathrm{a}}$ & $9.25 \pm 0.06^{\mathrm{a}}$ & 1.80 & 1.00 \\
\hline ME200 & $1.08 \pm 0.07^{b, c, d}$ & $1.43 \pm 0.04^{b, c, d}$ & $1.65 \pm 0.03^{b, c, d}$ & $2.21 \pm 0.06^{b, c, d}$ & $2.7 I \pm 0.07^{b, c, d}$ & $5.56 \pm 0.04^{b, c, d}$ & 1.08 & 0.6 \\
\hline ME400 & $1.61 \pm 0.04^{\mathrm{a}, \mathrm{b}, \mathrm{d}}$ & $2.00 \pm 0.05^{\mathrm{a}, \mathrm{b}, \mathrm{d}}$ & $2.53 \pm 0.04^{\mathrm{a}, \mathrm{b}, \mathrm{d}}$ & 3. $10 \pm 0.03^{\mathrm{a}, \mathrm{b}, \mathrm{d}}$ & $4.00 \pm 0.05^{\mathrm{a}, \mathrm{b}, \mathrm{d}}$ & $8.24 \pm 0.2 l^{a, b, d}$ & 1.61 & 0.89 \\
\hline ME600 & $2.10 \pm 0.03^{a, c}$ & $2.66 \pm 0.06^{\mathrm{a}, \mathrm{c}}$ & $2.98 \pm 0.05^{\mathrm{a}, \mathrm{c}}$ & $3.45 \pm 0.08^{a, c}$ & $5.01 \pm 0.05^{\mathrm{a}, \mathrm{c}}$ & $9.40 \pm 0.07^{\mathrm{a}, \mathrm{c}}$ & 1.83 & 1.02 \\
\hline
\end{tabular}

Each value represents mean \pm S.E.M $(n=6)$

against control, bagainst standard, cagainstME400mg/kg, dagainst ME600mg/kg; ${ }^{\text {a,b,c,d }}$ < 0 0.05; ME200: Methanol

extract 200mg/kg, ME400: Methanol extract 400mg/kg, ME600: Methanol extract 600mg/kg, HCTI 0: hydrochlorothiazide I0mg/kg, Control: animals treated with distilled water

\section{Effect of fractions on urine volume: diuretic activity}

Among the solvent fractions, only $600 \mathrm{mg} / \mathrm{kg}$ and $400 \mathrm{mg} / \mathrm{kg}$ of the aqueous fractions as well as the $400 \mathrm{mg} / \mathrm{kg}$ and $600 \mathrm{mg} / \mathrm{kg}$ of the butanol fraction and $600 \mathrm{mg} / \mathrm{kg}$ chloroform fractions produced a significant diuresis $(\mathrm{p}<0.05)$. The aqueous fraction produced diuresis which appeared to be a dose dependent $(\mathrm{r} 2=0.946 ; \mathrm{p}<0.05)($ Table 2$)$ AF200 did not produce a statistically significant diuresis compared to control throughout the $24 \mathrm{~h}$ period. AF400 and AF600 produced an increased diuresis starting from the first hour $(\mathrm{p}<0.05)$ when compared with control group.

Table 2 Effects of $80 \%$ methanol extract and fractions of W. somnifera roots on $24 \mathrm{~h}$ urine volume in rats

\begin{tabular}{|c|c|c|c|c|c|c|c|c|}
\hline \multirow{2}{*}{ Group } & \multicolumn{6}{|c|}{ Volume of urine $(\mathrm{mL})$} & \multirow{2}{*}{$\begin{array}{l}\text { Diuretic } \\
\text { action }\end{array}$} & \multirow{2}{*}{$\begin{array}{l}\text { Diuretic } \\
\text { activity }\end{array}$} \\
\hline & Ih & $2 \mathrm{~h}$ & $3 h$ & $4 h$ & $5 h$ & $24 h$ & & \\
\hline Control & $1.00 \pm 0.07$ & $1.33 \pm 0.06$ & $1.56 \pm 0.05$ & $2.03 \pm 0.04$ & $2.48 \pm 0.03$ & $5.13 \pm 0.04$ & 1.00 & \\
\hline HCTIO & $2.03 \pm 0.04^{\mathrm{a}}$ & $2.55 \pm 0.04^{\mathrm{a}}$ & $2.93 \pm 0.03^{a}$ & $3.39 \pm 0.06^{\mathrm{a}}$ & $4.76 \pm 0.12^{a}$ & $9.25 \pm 0.06^{\mathrm{a}}$ & 1.80 & 1.00 \\
\hline AF200 & $1.05 \pm 0.06^{b, c, d}$ & $1.40 \pm 0.05^{b, c, d}$ & $\mathrm{I} .62 \pm 0.0 \mathrm{I}^{\mathrm{b}, \mathrm{c}, \mathrm{d}}$ & $2.15 \pm 0.02^{b, c, d}$ & $2.58 \pm 0.03^{b, c, d}$ & $5.48 \pm 0.04^{b, c, d}$ & 1.07 & 0.59 \\
\hline AF600 & $I .7 I \pm 0.07^{\mathrm{a}, \mathrm{c}}$ & $2.15 \pm 0.04^{\mathrm{a}, \mathrm{c}}$ & $2.70 \pm 0.08^{\mathrm{a}, \mathrm{c}}$ & $3.05 \pm 0.06^{\mathrm{a}, \mathrm{c}}$ & $4.66 \pm 0.12^{\mathrm{a}, \mathrm{c}}$ & $9.12 \pm 0.07^{\mathrm{a}, \mathrm{c}}$ & 1.78 & 0.98 \\
\hline BF200 & $1.02 \pm 0.05^{b, f}$ & $1.36 \pm 0.02^{\mathrm{b}, \mathrm{f}}$ & $1.60 \pm 0.02^{b, e, f}$ & $2.10 \pm 0.02^{b, e, f}$ & $2.50 \pm 0.03^{b, e, f}$ & $5.27 \pm 0.04^{b, e, f}$ & 1.03 & 0.57 \\
\hline BF400 & $1.15 \pm 0.06^{b}$ & $I .5 \mathrm{I} \pm 0.04^{\mathrm{b}, \mathrm{f}}$ & $1.95 \pm 0.05^{\mathrm{a}, \mathrm{b}, \mathrm{f}}$ & $2.36 \pm 0.04^{a, b, f}$ & $3.03 \pm 0.06^{a, b, f}$ & $7.69 \pm 0.12^{a, b, f}$ & 1.50 & 0.83 \\
\hline BF600 & $1.4 I \pm 0.05^{a}$ & $1.88 \pm 0.07^{\mathrm{a}, \mathrm{e}}$ & $2.26 \pm 0.07^{\mathrm{a}, \mathrm{e}}$ & $2.68 \pm 0.08^{\mathrm{a}, \mathrm{e}}$ & $4.20 \pm 0.1 \mathrm{I}^{\mathrm{a}, \mathrm{e}}$ & $8.74 \pm 0.09^{\mathrm{a}, \mathrm{e}}$ & 1.70 & 0.94 \\
\hline CF200 & $1.01 \pm 0.05^{\mathrm{b}, \mathrm{h}}$ & $1.35 \pm 0.02^{\mathrm{b}, \mathrm{h}}$ & $1.57 \pm 0.02^{\mathrm{b}, \mathrm{h}}$ & $2.05 \pm 0.03^{\mathrm{b}, \mathrm{h}}$ & $2.49 \pm 0.03^{\mathrm{b}, \mathrm{h}}$ & $5.19 \pm 0.04^{\mathrm{b}, \mathrm{h}}$ & 1.01 & 0.56 \\
\hline CF400 & $1.10 \pm 0.04^{b}$ & $1.40 \pm 0.05^{\mathrm{b}, \mathrm{h}}$ & $1.62 \pm 0.04^{\mathrm{b}, \mathrm{h}}$ & $2.10 \pm 0.06^{\mathrm{b}, \mathrm{h}}$ & $2.60 \pm 0.07^{\mathrm{b}, \mathrm{h}}$ & $6.10 \pm 0.06^{\mathrm{b}, \mathrm{h}}$ & 1.19 & 0.66 \\
\hline CF600 & $1.33 \pm 0.04^{\mathrm{a}}$ & $1.73 \pm 0.08^{\mathrm{a}, \mathrm{g}}$ & $1.93 \pm 0.04^{\mathrm{a}, \mathrm{g}}$ & $2.33 \pm 0.07^{\mathrm{a}, \mathrm{g}}$ & $3.15 \pm 0.16^{\mathrm{a}, \mathrm{g}}$ & $7.98 \pm 0.15^{\mathrm{a}, \mathrm{g}}$ & 1.56 & 0.86 \\
\hline
\end{tabular}

Each value represents mean \pm S.E.M $(n=6)$

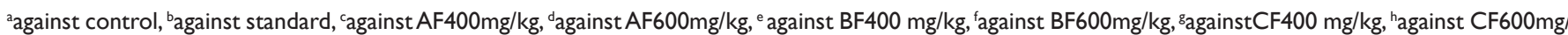
kg; a,b,c,d,e,f,g,h $<$ 0.05; AF200: aqueous fraction 200mg/kg, AF400: aqueous fraction 400mg/kg, AF600: aqueous fraction 600mg/kg, BF200: butanol fraction 200mg/ kg, BF400: butanol fraction 400mg/kg, BF600: butanol fraction 600mg/kg, CF200: chloroform fraction 200mg/kg, CF400: chloroform fraction 400mg/kg, CF600: chloroform fraction $600 \mathrm{mg} / \mathrm{kg}$, HCTI 0: hydrochlorothiazide $10 \mathrm{mg} / \mathrm{kg}$, Control: animals treated with the vehicle

The rats treated with butanol fraction also produced diuresis which appeared to be in a dose dependent manner ( $\mathrm{r} 2=0.942 ; \mathrm{p}<0.05$ ) (Table 2). BF400 and BF600 produced an increased diuresis starting from the third $(\mathrm{p}<0.05)$ and first hour $(\mathrm{p}<0.05)$, respectively.

Chloroform fraction at the dose of 200 and $400 \mathrm{mg} / \mathrm{kg}$ was devoid of significant diuretic effect. However, the fraction at $600 \mathrm{mg} / \mathrm{kg}$ produced an increased diuresis starting from the first hour $(\mathrm{p}<0.05)$ and continued up to $24 \mathrm{~h}(\mathrm{p}<0.05)$. Comparing the $80 \%$ methanol extract and the solvent fractions (aqueous, butanol and chloroform), the $80 \%$ methanol extract had better diuretic activity than the solvent fractions.

\section{Effect of $80 \%$ methanol extract on electrolyte content of the urine: saluretic activity}

The cumulative urine samples collected in the $24 \mathrm{~h}$ were analyzed for the electrolyte content $(\mathrm{Na}+, \mathrm{K}+$, and $\mathrm{Cl}-)$. ME400 and ME600 increased urinary sodium excretion by $54 \%$ and $69 \%$, respectively, which was significant compared to control group $(\mathrm{p}<0.05)$. Similarly, ME400 and ME600 resulted an increased potassium excretion by $32 \%$ and $37 \%$ which was significant when compared control $(\mathrm{p}<0.05)$. The maximum potassium excretion was resulted by HCT10 which is $46 \%$ $(\mathrm{p}<0.001)$ compared to control group (Table 3). 
Table 3 Effect of $80 \%$ methanol extracts of W. somnifera roots on urinary electrolyte

\begin{tabular}{|c|c|c|c|c|c|c|c|c|}
\hline \multirow{2}{*}{ Group } & \multicolumn{3}{|c|}{ Urinary Electrolyte Concentration (mmol/L) } & \multicolumn{3}{|c|}{ Saluretic Index } & \multirow{2}{*}{$\mathrm{Na}^{+} / \mathrm{K}^{+}$} & \multirow{2}{*}{$\mathrm{Cl} / / \mathrm{Na}^{+}+\mathrm{K}^{+}$} \\
\hline & $\mathrm{Na}^{+} \mathrm{Cl}^{-}$ & $\mathbf{K}^{+}$ & $\mathrm{Cl}^{-}$ & $\mathrm{Na}^{+} \mathrm{Cl}^{-}$ & $\mathbf{K}^{+}$ & $\mathrm{Cl}^{-}$ & & \\
\hline Control & $71.9 \pm 1.57$ & $53.0 \pm 2.41$ & $67.3 \pm 2.09$ & & & & 1.36 & 0.54 \\
\hline HCTIO & $\left.|26.0 \pm| .7\right|^{\mathrm{a}}$ & $77.3 \pm 1.21^{\mathrm{a}}$ & $121.0 \pm 1.90^{\mathrm{a}}$ & 1.75 & 1.46 & 1.80 & 1.63 & 0.60 \\
\hline ME200 & $90.7 \pm \mathrm{I} .35^{\mathrm{b}, \mathrm{c}, \mathrm{d}}$ & $59.3 \pm 1.88^{\mathrm{b}, \mathrm{c}, \mathrm{d}}$ & $87.5 \pm I .78^{b, c, d}$ & 1.26 & 1.12 & 1.30 & 1.53 & 0.58 \\
\hline ME400 & $110.4 \pm 1.50^{\mathrm{a}, \mathrm{b}, \mathrm{d}}$ & $69.7 \pm 1.57^{\mathrm{a}, \mathrm{b}}$ & $106.0 \pm 1.74^{\mathrm{a}, \mathrm{b}, \mathrm{d}}$ & 1.53 & 1.29 & 1.57 & 1.60 & 0.59 \\
\hline ME600 & $121.2 \pm 2.25^{\mathrm{a}, \mathrm{c}}$ & $72.6 \pm 2.14^{\mathrm{a}, \mathrm{b}}$ & $119.3 \pm 2.00^{\mathrm{a}, \mathrm{c}}$ & 1.68 & 1.37 & I.77 & 1.66 & 0.62 \\
\hline
\end{tabular}

Each value represents mean \pm S.E.M $(n=6)$ and was analyzed by ANOVA followed by Tukey post hoc multiple comparison test

against control, bagainst standard, cagainst ME400 mg/kg, ${ }^{d}$ againstME600 mg/kg; a,b,c,dp< 0.05; ME200: methanol extract $200 \mathrm{mg} / \mathrm{kg}$, ME400: methanol extract 400 $\mathrm{mg} / \mathrm{kg}$, ME600: methanol extract $600 \mathrm{mg} / \mathrm{kg}$, HCTI 0: hydrochlorothiazide $10 \mathrm{mg} / \mathrm{kg}$, Control: animals treated with distilled water

Effect of aqueous and butanol fractions on electrolyte content of the urine: saluretic activity

The aqueous fractions showed an increased pattern of urinary sodium excretion significantly at doses of $400 \mathrm{mg} / \mathrm{kg}$ and $600 \mathrm{mg} / \mathrm{kg}$ compared to control (Table 4). AF400 and AF600 increased sodium excretion by $44 \%(\mathrm{p}<0.05)$ and $57 \%(\mathrm{p}<0.05)$, respectively. Similarly, both AF400 and AF600 increased potassium and chloride excretion. AF400 enhance potassium and chloride excretion by $21 \%(\mathrm{p}<0.05)$ and $47 \%(\mathrm{p}<0.05)$, and AF600 increased by $33 \%(\mathrm{p}<0.05)$ and $63 \%$ $(\mathrm{p}<0.05)$, respectively.

Table 4 Effect of fractions of Withania somnifera roots on urinary electrolyte excretion in rats

\begin{tabular}{|c|c|c|c|c|c|c|c|c|}
\hline \multirow{2}{*}{ Group } & \multicolumn{3}{|c|}{ Urinary electrolyte concentration ( $\mathrm{mmol} / \mathrm{L})$} & \multicolumn{3}{|c|}{ Saluretic index } & \multirow{2}{*}{$\mathrm{Na}^{+} / \mathrm{K}^{+}$} & \multirow{2}{*}{$\mathrm{Cl} / \mathrm{Na}^{+}+\mathrm{K}^{+}$} \\
\hline & $\mathrm{Na}^{+} \mathrm{Cl}^{-}$ & $\mathbf{K}^{+}$ & $\mathrm{Cl}^{-}$ & $\mathrm{Na}^{+} \mathrm{Cl}^{-}$ & $\mathbf{K}^{+}$ & $\mathrm{Cl}^{-}$ & & \\
\hline Control & $71.9 \pm 1.57$ & $53.0 \pm 2.41$ & $67.3 \pm 2.09$ & & & & 1.36 & 0.54 \\
\hline HCTIO & $|26.0 \pm 1.7|^{\mathrm{a}}$ & $77.3 \pm 1.21^{\mathrm{a}}$ & $121.0 \pm 1.90^{\mathrm{a}}$ & 1.75 & 1.46 & 1.80 & 1.63 & 0.60 \\
\hline AF200 & $83.2 \pm 2.45^{b, c, d}$ & $56.2 \pm 3.34 \mathrm{b,d}$ & $80.9 \pm 2.23_{b, c, d}$ & 1.16 & 1.06 & 1.20 & 1.48 & 0.58 \\
\hline AF400 & $103.8 \pm 2.19^{\mathrm{a}, \mathrm{b}}$ & $63.9 \pm 2.42^{\mathrm{a}, \mathrm{b} 2}$ & $99.1 \pm 2.12_{\mathrm{a}, \mathrm{b}, \mathrm{d}}$ & 1.44 & 1.21 & $\mathrm{I} .47$ & 1.62 & 0.59 \\
\hline AF600 & $112.8 \pm 2.71^{a, b}$ & $70.6 \pm 2.21$ a & $109.8 \pm 2.32^{\mathrm{a}, \mathrm{b}, \mathrm{c}}$ & 1.57 & 1.33 & 1.63 & 1.60 & 0.60 \\
\hline BF200 & $77.9 \pm 1.71$ be,f & $54.7 \pm 3.11 \mathrm{~b}$ & $75.9 \pm 1.79 \mathrm{~b}, \mathrm{e}, \mathrm{f}$ & 1.08 & 1.03 & 1.13 & 1.42 & 0.57 \\
\hline BF 400 & $90.1 \pm 2.00_{a, b, f}$ & $59.9 \pm 2.94 \mathrm{~b}$ & $91.0 \pm 1.39_{a, b}$ & 1.25 & 1.13 & 1.35 & 1.50 & 0.61 \\
\hline BF600 & $105.6 \pm 1.98^{\mathrm{a}, \mathrm{b}, \mathrm{e}}$ & $64.8 \pm 1.93^{a, b}$ & $99.9 \pm 2.14 \mathrm{a}, \mathrm{b}$ & 1.47 & 1.22 & 1.48 & 1.63 & 0.59 \\
\hline CF200 & $73.6 \pm 2.25^{\mathrm{b.g}}$ & $53.4 \pm 2.59 \mathrm{~b}$ & $70.8 \pm 2.17_{\mathrm{b,g}}$ & 1.02 & $\mathrm{I} .0 \mathrm{I}$ & 1.04 & 1.38 & 0.56 \\
\hline CF400 & $75.1 \pm 1.91 \mathrm{~b}$ & $54.0 \pm 3.40^{\circ}$ & $73.9 \pm 2.18^{b}$ & 1.04 & 1.02 & 1.09 & 1.39 & 0.57 \\
\hline CF600 & $95.9 \pm 2.28 \mathrm{a,b}$ & $62.9 \pm 2.10^{\circ}$ & $92.3 \pm 2.79_{\mathrm{a}, \mathrm{b}}$ & 1.33 & 1.19 & 1.36 & 1.52 & 0.58 \\
\hline
\end{tabular}

Each value represents mean \pm S.E.M $(n=6)$

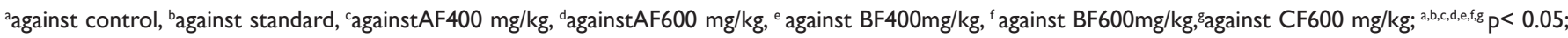
AF200: aqueous fraction $200 \mathrm{mg} / \mathrm{kg}$, AF400: aqueous fraction

400mg/kg, AF600: aqueous fraction 600mg/kg, BF200: butanol fraction 200mg/kg, BF400: butanol fraction 400mg/kg, BF600: butanol fraction 600mg/kg, CF200: chloroform fraction $200 \mathrm{mg} / \mathrm{kg}$, CF400: chloroform fraction $400 \mathrm{mg} / \mathrm{kg}$, CF600: chloroform fraction $600 \mathrm{mg} / \mathrm{kg}$, HCTI0: hydrochlorothiazide IOmg/kg, Control: animals treated with vehicle

\section{Electrolyte content of the extracts}

The electrolyte content of the extracts was examined $(\mathrm{Na}+, \mathrm{K}+$ and $\mathrm{Cl}-$ ) to rule out possibility of interference with water soluble salts could be present in the extracts and consequently interfere with the
The saluretic indices had also been calculated and among the aqueous fractions, equivalent results were obtained for $\mathrm{Na}+$ and $\mathrm{Cl}-$ between AF600 and HCT10 (1.57, 1.63 vs 1.75, 1.80) respectively.

Sodium excretion was significantly increased by BF400 $(25 \%$; $\mathrm{p}<0.05)$ and BF600 $(47 \%$; $<<0.05)$ compared with control. Similarly, BF400 and BF600 enhance $\mathrm{Cl}$ - excretion by $(35 \%$; $\mathrm{p}<0.05)$ and $(48 \%$; $\mathrm{p}<0.05)$ as compared with control. Among the chloroform fractions only the high dose produced statistically significant increase (33\%; $\mathrm{p}<0.05$ ) in sodium excretion (Table 4). 


\section{Effect of hydro-alcoholic extract and fractions on urine pH}

The $\mathrm{pH}$ of urine from groups treated with hydro-alcoholic extract was increased (Figure 1). But there was no any significant difference between the extracts and the control. The urinary $\mathrm{pH}$ measurement of the groups treated with fractions was shown to increase with dose though these increments were not statistically significant (Figure 1).

\section{Preliminary phytochemical screening}

The crude extract of the roots of $W$. somnifera was found to be positive for all of the tested secondary metabolites whereas the aqueous fraction was positive for the presence of alkaloids, tannins, saponins, flavonoids, glycosides, and the butanol fraction was positive for the presence of alkaloids, tannins, saponins, glycosides, while the chloroform fraction was positive for tannins, saponins, steroids, and terpenoids (Table 5).

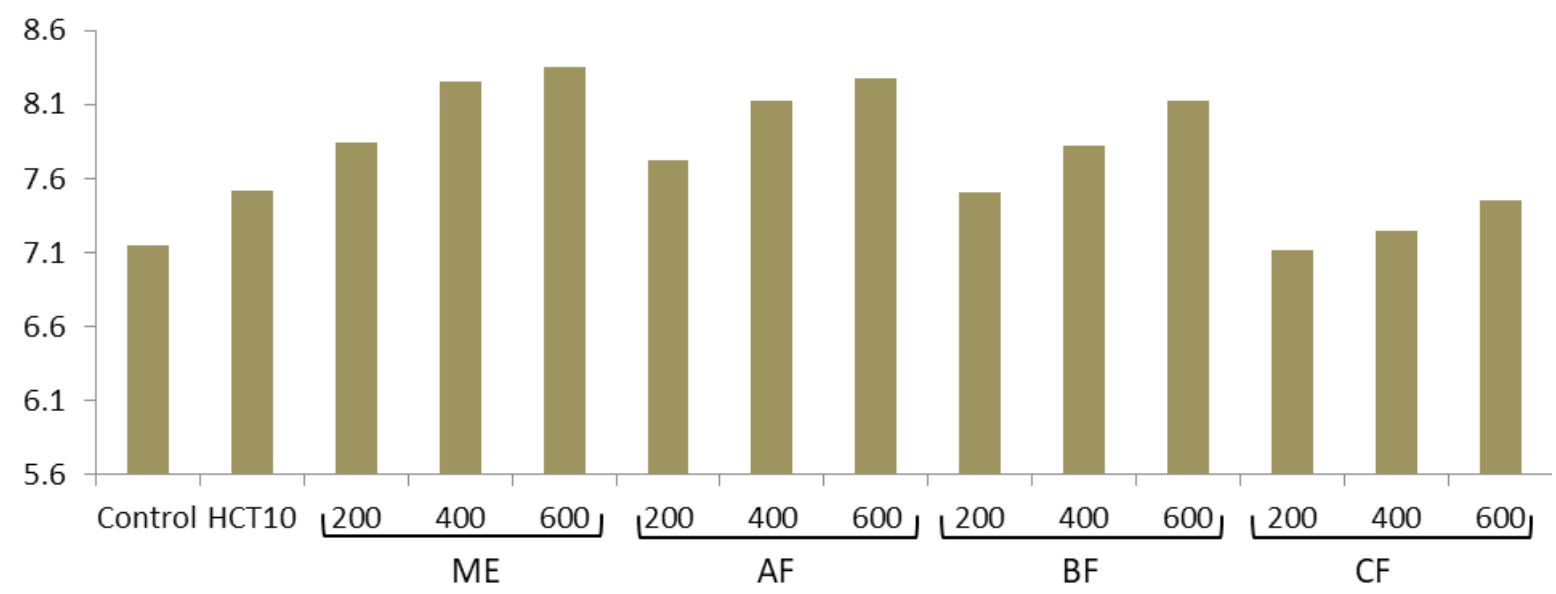

Figure I Urinary $\mathrm{pH}$ of rats treated with hydro-alcoholic extract of the root of W. somnifera. ME= $80 \%$ methanol extract of W. somnifera; $\mathrm{AF}$, aqueous fraction; $\mathrm{BF}$, butanol fraction; CF, chloroform fraction; HCTI0, hydrochlorothiazide $10 \mathrm{mg} / \mathrm{kg}$.

Table 5 Preliminary phytochemical screening of $80 \%$ methanol extract of roots of Withania somnifera roots and the solvent fractions

\begin{tabular}{|c|c|c|c|c|c|}
\hline \multirow{2}{*}{$\begin{array}{l}\text { Secondary } \\
\text { metabolite }\end{array}$} & \multirow{2}{*}{$\begin{array}{l}80 \% \text { methanolic } \\
\text { Extract }\end{array}$} & \multicolumn{3}{|c|}{ Solvent fractions } & \multirow{2}{*}{$\begin{array}{l}\text { Vehicle for } \\
\text { reconstitution }\end{array}$} \\
\hline & & Aqueous & Butanol & Chloroform & \\
\hline Alkaloids & + & + & + & - & - \\
\hline Tannins & + & + & + & + & - \\
\hline Saponins & + & + & + & - & - \\
\hline Terpenoids & + & - & - & + & - \\
\hline Steroids & + & - & - & + & - \\
\hline Flavonoids & + & + & - & - & - \\
\hline Glycosides & + & + & + & - & - \\
\hline Anthraquinons & + & - & - & - & - \\
\hline
\end{tabular}

$+=$ present $-=$ absent

\section{Discussion}

In view of urine output, the $80 \%$ methanol extract and solvent fractions showed an increase in diuresis that appeared to vary with dose and time. Compared to the solvent fractions, the $80 \%$ methanol extract produced a better diuretic effect. The medium dose of $80 \%$ methanol extract and aqueous fraction was able to produce significant effect beginning from the first hour. Whereas the medium dose of butanol fraction produce significant effect starting from the third hour and only the highest dose of chloroform fraction produced significant effect beginning from the first hour. This could be accounted by the lack of enough concentration of active components which are responsible for the diuretic activity at the low doses of chloroform and butanol fractions. It is therefore, possible to suggest that the active principles of the plant responsible for the diuretic effect could probably be more polar and semi-polar molecules.

The diuretic activity of extracts is considered to be good if the diuretic activity value is greater than 1.50 , moderate if the value is between 1.00 and 1.50 , mild if the value lies between 0.72 and 1.00 , and nil if the value is $<0.72 .{ }^{13}$ Based on the aforementioned category, the diuretic activities of the extract/fractions of $W$. somnifera rootsat their high doses were moderate type for the $80 \%$ methanol extract and mild for the solvent fractions as their values were 1.02, 0.98, 0.94 and 0.86 for ME600, AF600, BF600 and CF600, respectively.

In the present study, the extract/fractions increased electrolyte excretion. Thus it is reasonable to speculate that the diuretic effect of the fractions of $W$. somnifera roots was a saluretic type, in contrast to aquaretic type recorded in most phytodiuretic agents. ${ }^{14,15}$

The medium and high doses of the $80 \%$ methanol extract as well as aqueous and butanol fractions produced significant increase in $\mathrm{Na}+$ and $\mathrm{Cl}$ - excretion while only the highdose of chloroform fraction resulted in a significant difference in $\mathrm{Na}+$ and $\mathrm{Cl}$ - excretion compared with control. The ratio $\mathrm{Na}+/ \mathrm{K}+$ was calculated as an indicator for natriuretic activity. Values greater than 2.0 indicate a favorable natriuretic effect, while ratios greater than 10.0 indicate a potassiumsparing effect. ${ }^{14}$ 
$\mathrm{Na}+/ \mathrm{K}+$ values for the high doses of the $80 \%$ methanol extract, aqueous, butanol and chloroform fractions were 1.66, 1.60, 1.58 and 1.52 , respectively. This indicates that the extract/fractions have no potassium sparing effect. The ratio $\mathrm{Cl}-/[\mathrm{Na}++\mathrm{K}+]$ was calculated to estimate carbonic anhydrase (CA) inhibition. CA inhibition can be excluded at ratios between 1.0 and 0.80 . With decreasing ratios slight to strong $\mathrm{CA}$ inhibition can be assumed. ${ }^{16}$ The $\mathrm{Cl}-/$ $[\mathrm{Na}++\mathrm{K}+]$ value for the high doses of the hydroalcoholic extract, aqueous, butanol and chloroform fractions was $0.62,0.60,0.59$ and 0.58 , respectively. Therefore, it is reasonable to suggest that one of the possible mechanisms of action of the extract/fractions is CA inhibition. Alkalization of urine is also one of the possible effect resulted from inhibition CA enzyme. Therefore, measurement of urinary $\mathrm{pH}$ indicated a relatively higher $\mathrm{pH}$ for the treatment group than the negative controls. Components which act on the collecting tubule could increase urinary $\mathrm{pH} .{ }^{17}$ However, the potassium wasting effect of the crude and solvent fractions ruled out the possibility of having similar mechanism to that of the potassium sparing diuretics. Thus, this rise in urinary $\mathrm{pH}$ supports the notion that CA inhibition could be one possible mechanism of action of the extracts.

The active principle/s responsible for the diuretic effects of the $80 \%$ methanol extract and solvent fractions from W. somnifera is / are, so far, not known. Preliminary phytochemical analysis done on the crude extract and solvent fractions revealed the presence of different secondary metabolites. Flavonoids and saponins appeared to be responsible for the better diuretic activity of the crude extract and aqueous fraction. Studies have shown that saponins isolated from various plants inhibit the furosemide-sensitive $\mathrm{Na}+$-ATPase which is responsible for trans-cellular sodium reabsorption. ${ }^{18,19}$ This evidence explains the reason why the methanolic extract and aqueous fraction had a better saluretic activity in the present study.

\section{Conclusion}

The current study validates the claimed ethno medical use of $W$. somnifera in hypertension. The finding revealed that there is an increase in the volume of urine output as the polarity of the fractions increases, which indicate that the diuretic effect of the plant is attributed to more polar bioactive principles. Further research on safety and identification of active principles responsible for diuretic activity in an attempt to identify hits is recommended.

\section{Ethical approval}

Ethical approval was obtained from Institutional Review Board of College of Health Sciences of Addis Ababa University (CHS-AAU).

\section{Acknowledgments}

The authors would like to thank Addis Ababa University for their financial support. The authors would like to thank Traditional and Modern Medicine Research Directorate, Ethiopian Public Health Institute, for their laboratory facilities.

\section{Conflicts of interest}

Declare if any conflict of interest exists.

\section{Funding}

None.

\section{References}

1. Dipiro JT, Talbert RL, Yee GC, et al. Cardiovascular and renal disorders. In: pharmacotherapy a pathophysiologic approach. 7th edn. USA, New York: McGraw-Hill; 2008.

2. Khan A, Bashir S, Gilani AH. An in vivo study on the diuretic activity of Holarrhena antidysenterica. Afr J Pharm Pharmacol. 2012;6(7):454-458.

3. Saidulu C, Venkateshwar S, Rao G. Morphological studies of medicinal plant of Withania somnifer (L.) Dunal grown in heavy metal treated contaminated soil. Journal of Pharmacognosy and Phytochemistry. 2014;3 (1):37-42.

4. Asres K, Bucar F, Kartnig T, et al. Activiral actiity against Human Immunodeficiency Virus Type 1 (HIV 1) and Type 2 (HIV 2) of Ethnopharmacology Selected Ethiopian Medicinal Plants. Phytother Res. 2001;15(1):62-69.

5. Imtiyaz S, Ali J, Aslam M, et al. Withaniasomnifera: a potent unani aphrodisiac drug. International Research Journal Of Pharmaceutical and Applied Sciences. 2013;3(4):59-63.

6. Desta B. Ethiopian traditional herbal drugs. Part III: Anti-fertility activity of 70 medicinal plants. J Ethnopharmacol. 1994;44(3):199-209.

7. Debella A. Manual for phytochemical screening of medicinal plants. Addis Ababa, Ethiopia: Ethiopian Health and Nutrition Research Institute; 2002. p. $35-47$

8. Kushwaha S, Betsy A, Chawla P. Effect of Ashwagandha (Withania somnifera) root powder supplementation in treatment of hypertension. Studies on Ethno-Medicine. 2012;6(2):111-115.

9. Benjumea D, Abdala S, Hernandez-Luis, et al. Diuretic activity of Artemisia thuscula. J Ethnopharmacol. 2005;100(1-2):205-209.

10. Mukherjee PK. Evaluation of diuretic agents. In: Quality control of herbal drugs. USA: Business Horizon; 2002. pp. 123-129.

11. Debella A. Manual for phytochemical screening of medicinal plants. Addis Ababa, Ethiopia: Ethiopian Health and Nutrition Research Institute; 2002. p. 35-47.

12. Ayoola GA, Coker HA, Adesegun SA, et al. Phytochemical screening and antioxidant activities of some selected medicinal Plants used for malaria therapy in Southwestern Nigeria. Trop J Pharm Res. 2008;7(3):10191024

13. Vogel HG. Diuretic and saluretic activity. In: Drug Discovery and Evaluation: Pharmacological Assays. 3rd edn., 2007. Pp. 513-517.

14. Martin-Herreraa D, Abdala S, Benjumeaa D, et a. Diuretic activity of some Withania aristata Ait. fractions. J Ethnopharmacol. 2008;117(3):496-499.

15. Praveen KD, Suchita M. A comprehensive review on herbal remedies of diuretic potential. IJRPS. 2013;3(1): 41-51.

16. Tirumalasetty J, Chandrasekhar N, Naveen A. Evaluation of diuretic activity of ethanol extract of Beninca sahispida stem in Swiss albino rats. Journal of Chemical and Pharmaceutical Research. 2013;5(3):91-97.

17. Ives HE. Cardiovascular-renal drugs. In: Katzung BG. Masters SB, Trevor AJ, editors. Basic and clinical pharmacology. 12th edn. New York, USA: McGraw-HILL: 2012. p. 251-270.

18. Souza MA, Lara SL, Previatoa OJ, et al. Modulation of Sodium Pumps by Steriodal Saponins. Z Naturforsch C J Biosci. 2004;59(5-6):432-436.

19. Diniz LRL, Portella VG, Cardoso FM, et al. The effect of saponins from Ampelozizyphus amazonicus Ducke on renal $\mathrm{Na}+$ pumps' activities and urinary excretion of natriuretic peptides. BMC Complement Altern Med. 2012;12:40. 